\title{
A DERROTABILIDADE NO CASO DE TRANSFERENCIA DE SERVIDORES CIVIS OU MILITARES PARA INSTITUIÇÃO EDUCACIONAL CONGÊNERE
}

\author{
Mônica Tassigny ${ }^{1}$ \\ Fabiana Costa Lima de Sá \\ Luzélia Falcão Rocha Lima Guimarães ${ }^{3}$
}

\begin{abstract}
Resumo
O objetivo visado nesta pesquisa é entender se o texto normativo aplicado para o caso de transferência ex offício de servidores civis ou militares para localidade na qual não exista instituição educacional congênere pode ou não ser derrotável. Para alcançá-lo, desenvolveu-se pesquisa bibliográfica e de natureza qualitativa. Inicialmente, buscase analisar a exigência da congeneridade na interpretação firmada pelo Supremo Tribunal Federal quando do julgamento da Ação Direta de Inconstitucionalidade no 3.324, que conferiu interpretação conforme ao artigo $1^{\circ}$ da Lei no 9.536, de 11 de dezembro de 1997. Pretende-se mostrar que a remoção no interesse exclusivo da administração pública não deveria impedir a matrícula em instituição de ensino superior, sob pena de violação do direito do servidor público civil e do militar à educação e à convivência familiar. Depois, firma-se entendimento do que se pode compreender por derrotabilidade. Ao final da pesquisa, conclui-se que o texto normativo aplicável pode sim ser derrotado no caso de transferência de servidores públicos ou militares, estudantes, para local que não possua estabelecimento de ensino congênere ou em localidade próxima.
\end{abstract}

Palavras-Chave: Derrotabilidade. Servidores civis ou militares. Congeneridade.

\section{INTRODUÇÃO}

Neste estudo, indaga-se se a teoria da derrotabilidade das regras jurídicas pode ser utilizada quando os servidores civis ou militares, estudantes ou que tenham dependentes estudantes, forem transferidos por interesses exclusivos da Administração Pública, portanto, transferidos ex offício, para uma localidade que não possua instituição educacional congênere e nem exista em lugar próximo.

Há legislação brasileira aplicável, em regra, aos casos em que ocorram transferências de ofício de servidores civis ou militares estudantes ou que tenham dependentes estudantes, inclusive com interpretação já

\footnotetext{
${ }^{1}$ Professora Doutora do Programa de Pós-graduação em Administração de Empresas da Universidade de Fortaleza (UNIFOR). Email: monica.tass@gmail.com

${ }^{2}$ Doutoranda em Direito Constitucional pela Unifor, professora do Centro Universitário Estácio do Ceará-FIC e da Fanor Devry/Brasil. E-mail: fabianacl.sa@gmail.com

${ }^{3}$ Mestranda do Programa de Pós-Graduação em Direito Constitucional da Universidade de Fortaleza-UNIFOR. E-mail: luzeliafalcao@hotmail.com
} 
estabelecida pelo Supremo Tribunal Federal. No entanto, neste trabalho, pretende-se analisar se o texto normativo geralmente utilizado na solução destas situações é derrotável na situação excepcional em que não há instituição receptora congênere.

Para este caso, ainda não há decisão do Supremo Tribunal Federal, apesar de ter sido reconhecida a existência de repercussão geral ao Recurso Extraordinário nº 601580 (BRASIL, 2009), cujo objeto a ser ulteriormente julgado diz respeito à matéria. A pesquisa, então, justifica-se visto que objetiva apontar uma provável solução para o assunto.

A derrotabilidade das normas é tema atual e ainda pouco explorado no Brasil; e como afirma Alfonso García Figueroa (2012), professor Doutor da Universidade de Castilla- La Mancha, na era do neoconstitucionalismo a discussão tem girado mais sobre a derrotabilidade ou inderrotabilidade das normas do que em torno da polêmica sobre normas com estrutura de princípios e normas com estrutura de regras.

Esta pesquisa desenvolveu-se a partir de pesquisa bibliográfica em artigos científicos publicados em torno da matéria, documentos e dados obtidos na Internet e em bancos de dados com respaldo científico. O estudo foi desenvolvido tendo por base a doutrina do Direito Constitucional e da Hermenêutica Constitucional. No que se refere à abordagem, a pesquisa caracteriza-se como qualitativa. Em relação ao objetivo, é exploratória e explicativa.

Primeiramente, analisa-se a exigência da congeneridade, à luz da jurisprudência do Supremo Tribunal Federal, quando ocorrer transferência de ofício de servidor civil ou militar estudante. Em seguida, avalia-se a teoria da derrotabilidade, buscando firmar um entendimento sobre o seu significado para uma análise da possível aplicabilidade na situação apontada.

\section{A EXIGÊNCIA DA CONGENERIDADE PARA TRANSFERENCIA DE SERVIDORES CIVIS OU MILITARES A LUZ DA JURISPRUDENCIA DO SUPREMO TRIBUNAL FEDERAL}

A remoção de ofício dos servidores públicos civis ou militares estudantes que acarrete mudança de domicílio é matéria que demanda atenção legislativa específica para regulamentação da problemática que permita a estes ou aos seus dependentes a matrícula em instituição de ensino superior congênere na localidade de destino, independentemente da existência de vaga, em qualquer época do ano.

A Lei no 8.112, de 11 de dezembro de 1990, que dispõe sobre o regime jurídico dos servidores públicos civis da União, das autarquias e das fundações públicas federais, em seu art. 99, disciplinou a matéria para autorizar a matrícula em instituição de ensino congênere do servidor estudante nas hipóteses de remoção no interesse da administração.

O princípio da congeneridade, nesse caso, exige a semelhança de regimes jurídicos entre as instituições 
de ensino superior entre as quais se dará a transferência ex officio do servidor ou militar estudante, de forma que a mudança ocorra de escola privada para privada ou de pública para pública.

Posteriormente, com a edição da Lei de Diretrizes e Bases da Educação, adveio a possibilidade de regulamentação das transferências ex officio entre instituições de educação superior, o que foi efetivado pela Lei n ${ }^{\circ}$ 9.536, de 11 de dezembro de 1997, cujo artigo $1^{\circ}$ trouxe a possibilidade de matrícula, em qualquer época do ano e independentemente da existência de vaga, de servidores civis e militares estudantes, ou ainda de seus dependentes, que venham a ser removidos no interesse exclusivo da instituição. O dispositivo, diversamente do artigo 99 da Lei n 8.1 12, de 11 de dezembro de 1990, não elencou a exigência de congeneridade entre a instituição de origem e a de destino.

Considera-se que esse diploma legal acabou por revogar o disposto no artigo 99 da Lei no 8.112, de 11 de dezembro de 1990, visto que passou a regular inteiramente a matéria nela antes tratada concernente às hipóteses em que seria possível a transferencia de servidor público civil federal entre instituições quando a mudança de sede fosse justificada pela necessidade do serviço.

No entanto, diversamente do que exigia o regramento anterior, o artigo $1^{\circ}$ da citada norma deixou de impor como requisito para admissibilidade da transferencia ex officio de uma instituição de ensino superior para outra a observância do critério da congeneridade. O legislador passou a admitir que a mudança - que poderia ocorrer em qualquer época do ano e independentemente de vaga - se desse entre escolas vinculadas a qualquer sistema de ensino. Essa alteração, na prática, tornou admissível que servidores públicos civis ou militares estudantes, quando removidos por interesse exclusivo da administração, fossem matriculados em instituições de ensino superior públicas mesmo quando egressos de escolas particulares. Tal benefício também se estenderia aos seus dependentes que fossem estudantes, nos termos da novel legislação.

Prevalecendo então o entendimento de que o artigo $1^{\circ}$ da Lei no $9.536 / 97$ afastou a regra da congeneridade, sua aplicação irrestrita acabava por desconsiderar outros princípios de índole constitucional, de forma a malferir o princípio da isonomia e o princípio da autonomia conferido às universidades públicas, conforme estabelecido, respectivamente, no artigo 5ㅇ, I e 207 da Constituição Federal de 1988.

A despeito dos questionamentos suscitados em relação à constitucionalidade da aplicação desse preceito legal, deve ser levado em conta que essa autorização de mudança de universidade, independentemente de vaga ou em qualquer época do ano, para instituição congênere nas hipóteses que o servidor civil ou militar estudante é removido de ofício resguarda, por um lado, o princípio da unidade familiar manifestado na necessidade de resguardo da convivência familiar.

Nesse contexto, a interpretação das leis que visem essa coesão familiar, como é o caso em estudo, deve considerar que a família se sagra pela Constituição Federal em seu art. 206 como base da sociedade a merecer 
tutela especial do Estado enquanto instrumento finalístico para a promoção da dignidade humana destinada à realização da personalidade de seus integrantes (TEPEDINO, 2008). E essa coesão familiar não haveria como ser tutelada não fora a previsão legal que estende a possibilidade de transferência ex officio entre instituições congêneres aos dependentes estudantes do servidor ou militar removido.

E não é só, porquanto a norma em apreço também acaba por assegurar, por via oblíqua, seja atendida a pretensão legítima de continuidade dos estudos não apenas do agente transferido, mas também dos seus dependentes, tornando efetivo o direito à educação, que, por ostentar a condição de direito social, acaba por ser exigivel por todos os indivíduos em face do Estado, como forma de garantir a formação da personalidade humana necessária para o convício social (MUNIZ, 2002).

Além disso, no que se refere especificamente aos militares - cujas remoções que acarretam mudança de sede são mais comuns em razão das exigências peculiares da própria carreira, que tem como corolários a hierarquia e a disciplina - não seria razoável inadmitir a matrícula em instituição de ensino no local de destino, inviabilizando seu direito à educação, ou ainda não autorizar a transferência de ofício dos seus dependentes, privando ou prejudicando a convivência familiar.

Raciocínio inverso, que induzisse ao entendimento segundo o qual não thes seria permitido matricular-se no local do novo domicílio em outra instituição de ensino, a qualquer tempo e independentemente de vaga, violaria o princípio da isonomia e o princípio da proporcionalidade, em razão dos prejuízos suportados quando da remoção efetivada, prevalecendo apenas os interesses da administração pública.

Feitas estas considerações acerca da necessidade de reconhecimento desse direito de transferência de ofício de uma instituição de ensino superior para outra, segundo o disposto no supracitado artigo $1^{\circ}$, deve-se levar em conta que a proteção desses interesses legítimos (direito à educação e direito à unidade familiar) não podem ser levados ao extremo no sentido de serem garantidos por meios desnecessários, caso essa transferência não observe o critério da congeneridade entre as instituições de origem e aquela do local para onde se efetivará a transferência.

Ocorre que a interpretação conferida, ao levar em consideração os valores acima apontados, não pode ensejar violação do princípio da proporcionalidade quando a transferência ocorrer entre instituições de ensino superior que não guardem similitude entre os sistemas de ensino, como seria o caso de permitir a transferência de uma universidade privada para uma pública, sem a observância do processo seletivo em igualdade de condições com outras pessoas inseridas no grupo social.

Segundo Gilmar Mendes, ao apreciar o objeto da $\mathrm{ADI}$ n 3.324, a aplicação do critério da congeneridade seria estritamente proporcional nessa hipótese visto que concomitantemente garantiria a observância não apenas do princípio da autonomia universitária e da matrícula aos servidores públicos civis e militares estudantes quando 
transferidos de ofício, mas também preservaria os interesses dos servidores públicos civis ou militares e seus dependentes estudantes, sem qualquer ofensa ao interesse dos demais que não integram essas categorias, ou seja, a grande maioria da população brasileira (BRASIL, 2004).

Ocorre que a justificativa que autoriza a transferência entre instituições de ensino quando o servidor público civil ou militar estudante é transferido para outra localidade para atender o interesse exclusivo da administração não encerra fundamento razoável apto a autorizar a não observância do princípio da congeneridade. É que, conquanto essa peculiaridade decorra do regime jurídico diferenciado a que são submetidos por ostentarem a qualidade de agentes públicos, viola frontalmente o princípio da isonomia a transferência de ofício verificada entre instituições não congêneres, visto que os demais indivíduos não gozam de idêntico privilégio, ingressando nas universidades públicas apenas mediante submissão a processo seletivo.

A isonomia, princípio constitucional que demanda respeito às diferenças, decorre da necessidade de conferir um tratamento igualitário quando existir um fundamento razoável, o qual, segundo Robert Alexy, necessita de uma razão suficiente apta a justificar um tratamento diferenciado, sendo que, na hipótese de inexistência, torna imperioso um tratamento uniforme. Esse fundamento qualificado é resumido segundo o enunciado geral de que " [...] se não houver uma razão suficiente para a permissibilidade de um tratamento desigual, então, o tratamento igual é obrigatório" (ALEXY, 2014, p. 408).

Partindo dessa permissão, deve-se levar em consideração que a submissão dos militares ou servidores civis a um regime jurídico diferenciado que autoriza a mudança de sede por interesse exclusivo da Administração não é uma razão suficiente para permitir a diferença de tratamento em relação ao restante do grupo social, autorizado que os primeiros sejam matriculados em instituição não congênere, sem submeter-se a processo seletivo.

Diante disso, estaria sendo contrariado o princípio constitucional da isonomia, pois ao argumento de garantir e assegurar as prerrogativas dos servidores públicos civis ou militares que ostentam um regime jurídico diferenciado, estaria sendo comprometido o acesso à universidade pública e gratuita para o restante do grupo social.

A fim de lançar luzes sobre a necessidade de observância do critério da congeneridade é imperioso registrar que o Procurador-Geral da República, impugnando a sistemática de transferência permitida pelo art. $1^{\circ}$ da Lei no 9.536/97, interpôs ação direta de inconstitucionalidade, alegando que esse preceito normativo contrariaria o conteúdo axiológico dos artigos 5o, caput e inciso I; artigo 37, caput;; artigo 206, I a VII; artigo 208, inciso V, todos da Constituição Federal de 1988 (BRASIL, 2004).

A irresignação contra o preceito cingiu-se em torno da sua inconstitucionalidade, tendo em vista que a possibilidade de egressos de estabelecimentos de ensino superior privado serem transferidos para instituições 
integrantes do sistema de ensino público, ensejaria 1) um tratamento diferenciado como regra e não exceção, sem qualquer proporcionalidade entre os meios escolhidos para atingir o fim almejado; 2) violação da igualdade de acesso ao ensino, nos termos do artigo 206 da Constituição da República; 3) desrespeito ao princípio republicano, por pertencer a coisa pública a todos e não apenas a um grupo restrito; 4) malferimento do princípio da impessoalidade e moralidade, por descumprimento ao critério meritocrático da seleção, conforme artigo 208, V; 5) violação do princípio da autonomia universitária ao se permitir a transferência de uma instituição privada para uma pública (BRASIL, 2004).

A ação ajuizada, registrada no Supremo Tribunal Federal com no 3.324, sob a relatoria do Ministro Marco Aurélio, restou, por unanimidade, julgada parcialmente procedente para, sem redução de texto, conferir interpretação conforme ao artigo $1^{\circ}$ da Lei no 9.536, de 11 de dezembro de 1997, no sentido de tornar a transferência obrigatória entre instituições de ensino superior somente quando observado o critério da congeneridade entre a instituição de origem e a de destino do servidor civil ou militar e seus dependentes estudantes.

Tal julgamento, portanto, expurgou do ordenamento qualquer interpretação que não observe o princípio da congeneridade, de forma a inviabilizar as transferências ex officio de uma instituição de educação superior cujo sistema de ensino é privado para uma com um sistema de feição pública e na qual o ingresso somente é permitido mediante seleção, segundo o critério do merecimento.

Os fundamentos utilizados para reconhecer a procedência do pedido, adotando-se o princípio da congeneridade no Supremo Tribunal Federal, restou resumido nos seguintes termos (BRASIL, 2004, p.13):

[..] e®consentânea com a Carta da República previsão normativa asseguradora, ao militar e ao dependente estudante, do acesso à instituição de ensino na localidade para onde é removido. Todavia, a transferência do local do serviço não pode se mostrar verdadeiro mecanismo para lograr-se a transposição da seara particular para a pública, sob pena de se colocar em plano secundário a isonomia - artigo $5^{\circ}$, cabeça e inciso I -, a impessoalidade, a moralidade na Administração Pública, a igualdade de condições para o acesso e permanência na escola superior, prevista no inciso I do artigo 206, bem como a viabilidade de chegar-se a níveis mais elevados do ensino, no que o inciso $\mathrm{V}$ do artigo 208 vincula o fenômeno à capacidade de cada qual [...]

O entendimento firmado pelo Supremo Tribunal Federal de exigir a observância do critério da congeneridade conforma a interpretação do artigo $1^{\circ}$ da Lei no 9.536/96 com outros preceitos constitucionais, sem comprometer a satisfação dos interesses dos servidores civis ou militares estudantes que sejam transferidos no interesse da Administração acarretando mudança de sede. Isso porque, na medida em que ainda se permite a transferência ex officio entre instituições de ensino superior, observada a congeneridade, por outro mantêm-se o interesse do grupo social em exigir que as vagas das universidades públicas sejam preenchidas apenas por meio de processo seletivo.

O julgamento da ação, contudo, não encerrou a discussão acerca da matéria, porquanto - apesar de a 
matéria ter sido suscitada a título argumentativo quando da sua apreciação - os Ministros deliberaram por não enfrentar a temática respeitante à inexistência de estabelecimento de ensino congênere no local para onde o servidor civil ou o militar foram transferidos no interesse do serviço.

Seria, então, o caso de buscar em nosso ordenamento ou na doutrina solução constitucional que resolva definitivamente a questão, questionando-se se pode ser derrotável a vedação constante contida no julgamento da $\mathrm{ADI} n^{\circ} 3.324$, quando não houver estabelecimento de ensino congênere no local para o qual for transferido o servidor civil ou militar estudante.

\section{A DERROTABILIDADE APLICADA NO CASO DA EXIGÊNCIA, PARA SERVIDORESCIVIS OU MILITARES, DE TRANSFERENCIA PARA INSTITUIÇÃO EDUCACIONAL CONGÊNERE}

Precisa-se, antes de enfrentar a problemática levantada, apresentar uma definição para a derrotabilidade (defeasibility). Antes de procurar saber se a regra utilizada no caso de transferência de servidores civis ou militares para instituições educacionais congêneres é ou não derrotável, precisa-se estabelecer o que se compreende por derrotabilidade.

A utilização da teoria da derrotabilidade das regras jurídicas remonta ao ensaio The Ascription of Responsibility and Rights (1948-1949), escrito pelo jusfilósofo inglês Hebert L.A. Hart, cuja ideia central estava assentada na ideia de caracterizar os conceitos jurídicos para daí compreender as contingências que afastariam a aplicação dessas regras.

Conquanto não exista tradução correspondente na língua portuguesa para a palavra defeasibility, convencionou-se utilizar o termo correspondente derrotabilidade. Herbert L.A Hart assevera em seu texto que tomou emprestado e alargou o sentido da palavra inglesa defeasible, que seria usada para um tipo de propriedade que estaria sujeita à extinção ou derrota quando houvessem contingências diferentes, mas que permaneceria intacta caso estas não se concretizassem.

Herbert L.A Hart sustenta em seu texto, partindo da premissa de que o direito é indeterminado e os conceitos jurídicos são vagos ('vaguenesse of character') que, no momento da aplicação das regras jurídicas, surgem circunstâncias não previstas inicialmente que acabam por derrotar a regra geral. (HART, 1948-1949)

Para fundamentar a teoria da derrotabilidade das regras, Hart (1948-1949, p. 175) exemplifica com a descrição da seguinte situação:

[...] When the student has learnt that in English law there are positive conditions required for the existence of a valid contract, [...] his understanding of the legal concept of a contract is still incomplete[...]. For these conditions, although necessary, are not always sufficient and he has still to learn what can defeat a claim that there is a valid contract, even though all these 
conditions are satisfied. That is the student has still to learn what can follow on the word " unless" which should accompany the statement of these conditions [...] .

Conforme originariamente proposta por Hebert L.A Hart, a apresentação da sua teoria sobre a derrotabilidade funda-se na utilização da expressão 'a menos que' após a regra jurídica. Com isso, quando da sua aplicação prática, todas as regras jurídicas quando aplicadas em casos difíceis deixariam de ser aplicadas ante o surgimento de circunstâncias relevantes, capazes de excepcionariam a consequência normativa prevista originariamente na regra, derrotando-a. (HART, 1948-1949)

O autor alemão Carster Bäcker (2011, p. 60) com muita clareza afirma que "[...] derrotabilidade deve ser entendida como a capacidade de acomodar exceções. Se olharmos para as regras, elas têm, em geral, exceções. Essas exceções não podem ser enumeradas de forma conclusiva [...]”.

Existem normas com estrutura de regras e normas com estrutura de princípios, mas por razõ es práticas não se pretende aqui apresentar as várias discussões existentes sobre esta diferenciação, pois seria preciso um desenvolvimento cuidadoso e amplo sobre o tema e busca-se aqui apresentar um trabalho com objetividade em busca da resposta para o qual se propõe. E como a norma a ser analisada diante da possibilidade da aplicação da teoria da derrotabilidade é nitidamente classificada como uma norma com estrutura de regra, entende-se dispensável o desenvolvimento de estudo sobre a diferenciação entre regras e princípios.

Para Carster Bäcker (2011) as regras são derrotáveis, mas os princípios não são derrotáveis; na aplicação das regras podem surgir exceções, mas na aplicação dos princípios estas não podem surgir, pois o princípio é visto como um mandamento de otimização e, assim, já acomoda todas as circunstâncias dos casos futuros, já incorpora em sua estrutura todas as exceções possíveis.

Geralmente, para as regras gerais existem exceções e o legislador ao elaborá-las poderá, inclusive, enumerar expressamente algumas exceções para a aplicação das regras estabelecidas, mas ele não conseguirá prever todas as situações futuras, todas as circunstâncias que poderão vir a ocorrer e que poderão ser acomodadas como exceções à regra geral.

O legislador ao elaborar a regra jurídica geral pode enumerar algumas exceções para a sua aplicação quando consegue prevê-las, mas não conseguirá enumerar todas as exceções que podem ser acomodadas por aquela regra jurídica, não conseguirá prever todas as exceções que podem ocorrer nos casos futuros, então, não é possível enumerar todas as possibilidades.

A incapacidade humana de prever todas as situações possíveis e a estrutura da regra jurídica como mandamento definitivo são fatores que dão origem a derrotabilidade. Como não é viável prever todas as exceções que podem ser acomodadas pela regra, não pode ser criada uma regra sem exceções. "[...] Se as condições de uma regra são satisfeitas, então a conclusão se segue, a menos que ocorra uma exceção, ou seja, se $a$, então $b$, a menos que $c[. .]$.$" (BÄCKER, 2011, p. 68).$ 
Caso a condição de uma regra seja satisfeita, geralmente, segue-se a conclusão, mas pode surgir uma exceção e a conclusão não ser verificada; a regra é aplicável "a menos que” surja uma exceção. Geralmente, quando a condição de uma regra é satisfeita, efetua-se a conclusão, "a menos que" surja uma exceção não prevista. Neste caso, a conclusão não se realiza ainda que a condição seja satisfeita.

A regra jurídica é derrotável, ou seja, a conclusão é superável diante de circunstâncias não previstas explicitamente na regra. Ainda que a situação se enquadre na hipótese normativa, a regra jurídica pode ser derrotada, pode ser afastada e não gerar a consequência prevista; a exceção à regra pode não ser explícita, mas implícita.

A regra jurídica caracteriza-se por prever uma hipótese fática e estabelecer a consequência jurídica no caso de sua ocorrência. A possibilidade da derrotabilidade da regra jurídica indica que a regra pode não ser aplicada diante de um caso concreto, mesmo ocorrendo todas as condições necessárias para a sua aplicação, quando surgir uma exceção considerada relevante, mas que não foi prevista expressamente. Mas, a regra derrotada para aquele caso continuará sendo aplicada para os demais casos previstos na proposição normativa.

Levando em consideração os ensinamentos de Friedrich Müller melhor dizer que o texto normativo é derrotável e não a norma, já que a norma é o resultado da interpretação e aplicação do texto normativo ao caso concreto, pois a norma não coincide com o texto normativo. "[...] O teor literal expressa o 'programa da norma', a 'ordem jurídica' [...]. Pertence adicionalmente à norma, em nível hierárquico igual, o âmbito da norma, i. e, o recorte de realidade social na sua estrutura básica [...]”. (MÜLLER, 2005, p.42). Então, não há, na verdade, a derrotabilidade da norma, mas sim a derrotabilidade do texto normativo ou do programa da norma.

Indaga-se se o texto normativo que disciplina a transferência de servidores civis ou militares estudantes para instituições educacionais congêneres é derrotável na situação de remoção ou transferência ex officio para local em que não tenha instituição educacional congênere e nem exista em localidade próxima. No tópico anterior foi identificado este texto normativo. Vale lembrar, de forma concisa, o que foi explanado para se enfrentar o questionamento levantado.

Prevalece o entendimento de que para servidores civis ou militares estudantes removidos de ofício, quando a remoção acarreta transferência de domicílio, é permitido a estes ou aos seus dependentes a matrícula em instituição superior de ensino congênere na localidade de destino, independentemente da existência de vaga, em qualquer época do ano.

Segundo o critério da congeneridade a transferência deve ser de instituição privada para privada ou de pública para pública, pois é uma exigência a semelhança de regimes jurídicos entre as instituições de ensino superior entre as quais se dará a transferência ex officio do servidor civil ou militar estudante.

O art. 99 da Lei 8.112, de 11 de dezembro de 1990, disciplinava a matéria autorizando a matrícula em 
instituição de ensino congênere do servidor estudante nas hipóteses de remoção no interesse da administração, mas foi revogado.

Diferentemente do que estabelecia o regramento anterior, o artigo $1^{\circ}$ da Lei no 9.536 , de 11 de dezembro de 1997, deixou de impor a exigência da congeneridade. Passou a admitir mudança entre instituições vinculadas a qualquer sistema de ensino e que poderia acontecer em qualquer época do ano e independentemente de vaga. Tornou possível, quando ocorrer a remoção ou a transferência por interesse exclusivo da administração de servidores públicos civis ou militares estudantes, a matrícula em instituições de ensino superior públicas mesmo quando egressos de instituições privadas, bem como de seus dependentes estudantes.

O Supremo Tribunal Federal foi chamado a encarar a matéria na ADI n 3.324. O Procurador Geral da República alegou na referida ação direta de inconstitucionalidade que esse preceito normativo contrariaria o conteúdo axiológico dos artigos 5\%, caput e inciso I; artigo 37, caput; artigo 206, I a VII; artigo 208, inciso V da Constituição Federal de 1988 (BRASIL,2004).

A ação ajuizada foi julgada, por unanimidade, parcialmente procedente. Conferiu-se interpretação conforme a Constituição ao artigo $1^{\circ}$ da Lei no 9.536, de 11 de dezembro de 1997, no sentido de tornar a transferência obrigatória entre instituições de ensino superior somente quando observado o critério da congeneridade entre a instituição de origem e a de destino do servidor civil ou militar e seus dependentes estudantes.

A interpretação dada ao texto normativo foi conforme os preceitos constitucionais e no sentido de ser necessária a exigência da congeneridade; entendendo que não acarretaria, ainda assim, o comprometimento da satisfação dos interesses dos servidores civis ou militares estudantes que sejam transferidos no interesse da Administração acarretando a mudança de domicílio. Isso porque, na medida em que ainda se permite a transferência ex officio entre instituições de ensino superior, observada a congeneridade, por outro se resguarda o interesse do grupo social em exigir que as vagas das universidades públicas sejam preenchidas apenas por meio de processo seletivo, portanto observa-se também a isonomia e a autonomia universitária.

Assim, continua a ser aplicado o art. $1^{\circ}$ da Lei no 9.536 para regulamentar a matéria, mas deve ser aplicado com a interpretação dada pelo Supremo Tribunal Federal. Trata-se de uma regra geral em que o legislador permitiu a sua não aplicação quando o deslocamento do interessado na transferência se der em razão de concurso público para assumir cargo efetivo, assumir cargo comissionado ou função de confiança.

Mas, não há nenhuma previsão legislativa específica e nem jurisprudencial solucionando o caso de transferência ou remoção de ofício de servidor civil ou militar para local em que não há estabelecimento educacional congênere e nem em localidade próxima. Indaga-se, portanto, a possibilidade da aplicação da derrotabilidade para esta situação apontada. 
Nos ensinamentos de Carster Bäcker (2011) a norma com estrutura de regra é derrotável e a derrotabilidade é a capacidade da regra acomodar exceções, pois o legislador poderá, inclusive, prever expressamente algumas exceções, mas não poderá enumerá-las de forma conclusiva.

O legislador ao elaborar o texto normativo geral pode enumerar expressamente algumas exceções para a sua aplicação quando consegue prevê-las, mas não conseguirá enumerar todas as exceções que podem ser acomodadas por aquele texto, pois não conseguirá prever todas as exceções que podem ocorrer nos casos futuros.

No caso analisado o texto normativo a ser aplicado é o do art. $1^{\circ}$ da Lei 9.536 que ganhou interpretação conforme a Constituição e, assim, passou-se a ser exigida a congeneridade para a sua aplicação. A exceção expressamente prevista é aplicável quando o deslocamento do interessado na transferência se der em razão de concurso público para assumir cargo efetivo, assumir cargo comissionado ou função de confiança.

Entende-se que, quando o caso concreto não for uma circunstância prevista como exceção, deve-se aplicar o texto normativo geral, pois quando satisfeita a condição de um programa normativo, geralmente, seguese a conclusão.

Mas, pode surgir uma exceção e a conclusão não ser verificada; a regra é aplicável "a menos que” surja uma exceção. Geralmente, quando a condição de uma regra é satisfeita, efetua-se a conclusão, "a menos que" surja uma exceção não prevista. Neste caso, a conclusão não se realiza ainda que a condição seja satisfeita (BÄCKER, 2011, p. 68).

Ainda que a situação de servidores civis ou militares transferidos ou removidos de ofício para local em que não tenha instituição educacional congênere e nem exista instituição receptora congênere em localidade próxima, quando for estudante ou tiver dependente estudante, se enquadre no texto normativo geral, pode este ser derrotado; pode o texto normativo ser derrotado e não gerar a consequência prevista. Pois a possibilidade da derrotabilidade indica que o texto normativo pode não ser aplicado diante de um caso concreto, mesmo ocorrendo todas as condições necessárias para a sua aplicação, quando surgir uma exceção considerada relevante, mas que não foi prevista expressamente.

Não entende ser proporcional ou razoável a aplicação do texto normativo geral para esta situação excepcional, pois seria extremamente injusto que um servidor civil estudante, militar estudante ou seus dependentes estudantes ficassem desprovidos da possibilidade de dar continuidade aos estudos quando ocorrer transferência de ofício para local em que seja impossível atender o critério da congeneridade. E, inclusive, colocando até em risco a coesão familiar.

Ainda vale ressaltar que no texto original da lei regulamentadora do assunto o legislador passou a admitir que a mudança, que poderia ocorrer em qualquer época do ano e independentemente de vaga, se desse entre instituições vinculadas a qualquer sistema de ensino. Tornou admissível que servidores públicos civis ou militares 
estudantes, quando removidos por interesse exclusivo da administração, fossem matriculados em instituições de ensino superior públicas mesmo quando egressos de estabelecimentos particulares. Tal benefício também se estenderia aos seus dependentes que fossem estudantes. Portanto, é bom frisar que a exigência da congeneridade adveio de interpretação firmada pelo Supremo Tribunal Federal.

Lembrando os ensinamentos de Robert Alexy ao apontar que um tratamento diferenciado somente é justificável diante de uma razão suficiente. Agora, nesta hipótese, torna-se imperioso um tratamento não isonômico, desconsiderando como único critério de seleção o mérito para ingresso em instituições públicas. Portanto, não é obrigatório o tratamento igualitário, pois só o é "se não houver uma razão suficiente para a permissibilidade de um tratamento desigual, então, o tratamento igual é obrigatório” (2014, p. 408).

E a situação analisada é relevante quando se passa a levar em consideração que a Constituição Federal de 1988 também assegura o direito à educação e o princípio da unidade familiar manifestado na necessidade de resguardo da convivência familiar. Assim, entende-se ser pautado na proporcionalidade e razoabilidade o afastamento da exigência do critério da congeneridade quando na localidade de destino ou em local próximo não tenha instituição educacional receptora congênere para que seja efetivada a transferência de ofício em qualquer época do ano, independentemente de vaga de servidor civil ou militar estudante ou de seus dependentes estudantes. Assegurando-se o direito de continuidade dos estudos, direito social fundamental daqueles, tornando efetivo o direito à educação e também resguardando a unidade familiar. Mas, ressalta-se que o texto normativo derrotado para este caso específico continuará sendo aplicado para os demais casos que se enquadram no texto normativo geral.

\section{CONCLUSÃO}

Como visto, a Lei no 9.536, de 11 de dezembro de 1997, em seu artigo $1^{\circ}$ passou a admitir a transferência ex officio entre instituições de ensino superior, em qualquer época do ano e independentemente de vaga, de servidores civis e militares estudantes, ou ainda seus dependentes estudantes, quando a remoção que acarretasse a mudança de domicílio ocorresse no interesse exclusivo da administração pública. Contudo, esse diploma não mais impôs como requisito a regra da congeneridade, diversamente da disciplina traçada pelo artigo 99 da Lei no 8.112, de 11 de dezembro de 1990, permitindo que essa mudança se desse entre instituições vinculadas a qualquer regime de ensino, seja público ou privado.

A edição dessa regra no ordenamento pátrio justifica-se pela necessidade de proteção dos interesses legítimos dos servidores civis ou militares estudantes que são removidos para outra localidade no interesse exclusivo do serviço público, porquanto negar-lhes a pretensão de matricularem-se em outra instituição de ensino, viola não apenas o direito à educação desses como também afastaria o direito à uma convivência familiar. 
Por outro lado, essa previsão possui o inconveniente de não exigir que a transferência ocorra entre instituições congêneres - de pública para pública ou privada para privada - permitindo a matrícula em instituições públicas, cujo ingresso se dá apenas mediante seleção, de alunos egressos de escolas particulares. Restariam então violados o princípio da isonomia e o princípio da autonomia das universidades públicas.

Mostrou-se que, na Ação Direta de Inconstitucionalidade no 3.324, o Supremo Tribunal Federal conferiu interpretação conforme ao reportado artigo de lei no sentido de afastar qualquer entendimento que não considere o princípio da congeneridade, de forma a tornar a evitar a transferência de uma instituição de ensino superior vinculada ao regime privado para uma de natureza pública, sem observância do critério da competente seleção, na qual é aferido o merecimento.

Para solução da lacuna teórica relativa à inexistência de universidade congênere no local para onde o servidor civil ou o militar forem transferidos no interesse do serviço, foi apresentada uma definição de derrotabilidade (defeasibility), compreendida como a capacidade do texto normativo de acomodar exceções não expressamente previstas pelo legislador, dada sua limitação de prever exaustivamente todas as possibilidades de exceções futuras.

Para solução da problemática, partindo-se do estudo dessa teoria, deve ser considerado como texto normativo a ser aplicado o artigo $1^{\circ}$ da Lei 9.536, de 11 de dezembro de 1997, de acordo com a interpretação conforme dada pelo Supremo Tribunal Federal quando do julgamento da Ação Direta de Inconstitucionalidade no 3.324, sendo que a exceção não expressamente prevista desse texto normativo seria a hipótese de inexistir estabelecimento de ensino superior congênere na localidade para a qual o servidor ou militar estudante venha a fixar domicílio.

Segundo o objetivo proposto nesta pesquisa e utilizando-se do referencial teórico apresentado, chega-se à conclusão de que é derrotável o texto normativo que autoriza a matrícula em instituição de ensino superior em qualquer época do ano e independentemente de matrícula, afastando-se o princípio da congeneridade na hipótese de inexistir estabelecimento de ensino congênere à de origem no local para o qual o servidor ou militar estudante, ou ainda seus dependentes estudantes, venham a residir em razão de remoção efetivada no interesse exclusivo da administração pública.

\section{THE DEFEASIBILITY IN THE TRANSFER CASE OF CIVILIAN OR MILITARY SERVERS TO THE CONGENER EDUCATIONAL INSTITUTION}

\section{Abstract}

The intended objective of this research is to understand if the normative text applied to the case of ex officio 
transfer of civil or military servers to location in which there is no congener educational institution may or may not be defeasible. To achieve it, it has developed literature and qualitative research. Initially, seeks to analyze the requirement of congeneracy in the interpretation settled by the Supreme Court when of judgement of the Direct Unconstitutionality Action no 3324, which gave interpretation according to Article 1 of Law no 9536, of December 11, 1997. It is intended to show that removing in the exclusive interest of the public administration should not prevent enrollment in higher education institution, under penalty of violation of right of the civilian public servant and military to education and family life. Then, it firm understanding of what can be understood by defeasibility. At the end of the study, it is concluded that the relevant normative text can indeed be defeated in case of transfer of public servants or military, students, to place that lacks educational establishment congener or in nearby locality.

Keywords: Defeasibility. Civilian or military servers. Congeneracy.

\section{REFERENCIAS}

ALEXY, R. Teoria dos Direitos Fundamentais. Tradução de Virgílio Afonso da Silva. São Paulo: Malheiros, 2014.

BÄCKER, C. Regras, princípios e derrotabilidade. Tradução de Tiago Lopes Mosci. Revista Brasileira de Estudos Políticos. Belo Horizonte. n. 102, p. 55- 82, jan./jun. 2011.

BRASIL. Constituição da República Federativa do Brasil. 48 ed. São Paulo: Saraiva, 2013.

BRASIL. Lei $\mathrm{n}^{\circ}$ 8.112, de 11 de dezembro de 1990. Disponível em: <http://www.planalto.gov.br/ccivil_03/leis/L8112cons.htm>. Acesso em: 04 /11/ 2015.

Lei $\mathrm{n}^{\circ}$ 9394, de 20 de dezembro de 1996. Estabelece as diretrizes e bases da educação nacional. Disponível em: <http://www.planalto.gov.br/ccivil_03/Leis/L9394.htm>. Acesso em: 12/12/2015.

Lei no 9.536, de 11 de dezembro de 1997. Disponível em: <http://www planalto.gov.br/ccivil_03/leis/L9536.htm>.Acesso em: 20/11/2015.

Supremo Tribunal Federal. Pleno. ADI 3.324/ DF. 16/01/2004. Disponível em: <http://www.stf.jus.br>. Acesso em: 03/12/ 2015.

Supremo Tribunal Federal. RE 601580. DF. 27/02/2009. Disponível em: <http://www.stf.jus.br/portal/processo/verProcessoAndamento.asp?incidente=2691334> . Acesso em: 11/12/2015.

Advocacia Geral da União. Parecer AGU/RA-02/04. DF, 17/01/ 2004. Disponível em: <http://www.agu.gov.br/atos/detalhe/8440>. Acesso em: 10/12/ 2015.

FIGUEROA, Alfonso García. Neoconstitucionalismo, derrotabilidade e razão prática. Tradução de Eduardo Ribeiro Moreira. Revista de Direito Constitucional e Internacional. São Paulo, ano 20, n. 79, p. 11-33, abr./jun. 2012.

HART, H. L. A. The Ascription of Responsibility and Rights. Aristotelian Society, New Series, v. 49, p. 171-194, 1948 - 1949. Disponível em http ://www .umiacs .umd .edu/ horty/couses/readings/hart-1948ascription.pdf. $>$ Acesso em: $04 \mathrm{dez} .2015$.

MÜLLER, Friedrich. Métodos de trabalho do Direito Constitucional. Tradução de Peter Naumann. Rio de Janeiro: Renovar, 2005. 
MUNIZ, Regina Maria Fonseca. O Direito à Educação. Rio de Janeiro: Renovar, 2002, 581p.

TEPEDINO, Gustavo. Temas de Direito Civil. 4. ed. Rio de Janeiro: Renovar, 2008.

Trabalho enviado em 31 de julho de 2016.

Aceito em 26 dejaneiro de 2017. 